\title{
Protein Synthesis Inhibition Blocks the Induction of Mossy Fiber Long-Term Potentiation In Vivo
}

\author{
Edwin J. Barea-Rodríguez, Domingo T. Rivera, David B. Jaffe, and Joe L. Martinez Jr \\ University of Texas at San Antonio, Division of Life Sciences, San Antonio, Texas 78249
}

\begin{abstract}
Protein synthesis inhibitors block the maintenance of NMDA receptor-dependent long-term potentiation (LTP) both in vivo and in vitro. Protein synthesis inhibitors block mossy fiber(MF) LTP maintenance in vitro, but little is known about the effect of protein synthesis inhibitors on either induction or maintenance in MFLTP in vivo. Here we study the role of protein synthesis in the induction of long-term potentiation at the mossy fiber-CA3 hippocampal synapse in vivo in anesthetized rats. The protein synthesis inhibitor anisomycin was administered at different doses $(0.04,10$, or $40 \mathrm{nmol})$ into area CA3 $15 \mathrm{~min}$ before delivering high-frequency stimulation (two times at $100 \mathrm{~Hz}, 1 \mathrm{sec}$ ). Anisomycin blocked MF-LTP induction in a dose-dependent manner; both 40 and $10 \mathrm{nmol}$ blocked MF-LTP induction, but a lower dose of $0.04 \mathrm{nmol}$ was without effect. The inhibitory effect of
\end{abstract}

anisomycin on protein synthesis was determined by measuring the incorporation of $\left[{ }^{35}\right.$ S]methionine into the newly synthesized proteins. Percentages of protein synthesis inhibition were determined by comparing $\left[{ }^{35} \mathrm{~S}\right]$ incorporation of anisomycin-treated samples with vehicle controls. Doses of $0.04,10$, or $40 \mathrm{nmol}$ of anisomycin produced 21,82 , or $83 \%$ inhibition of [ ${ }^{35}$ S]methionine incorporation, respectively. The effect of anisomycin was verified using a single dose of the protein synthesis inhibitor cycloheximide (40 nmol). Cycloheximide also blocked MF-LTP induction. These results suggest that protein synthesis plays an important role in the induction of mossy fiber long-term potentiation in vivo.

Key words: anisomycin; CA3; mossy fibers; hippocampus; long-term potentiation; cycloheximide and opioids
Long-term potentiation (LTP) refers to a long-lasting increase in amplitude of synaptic responses evoked in a monosynaptic pathway after high-frequency activation of specific afferent fibers (Bliss and Lomo, 1973). LTP is observed in the hippocampus, a brain structure associated with learning and memory (Scoville and Milner, 1957), suggesting that LTP is associated with learning and memory processes (Teyler and Discenna, 1984). The hippocampus displays at least two forms of LTP, one that is NMDA receptor-dependent (Harris et al., 1984) and one that NMDA receptor-independent and opioid receptor-dependent (Harris and Cotman, 1986; Derrick et al., 1991). NMDA receptor-dependent LTP is comprised of two processes, induction and maintenance. The maintenance process has two phases, an early phase (1-3 hr), which is protein synthesisindependent, and a late phase $(>3 \mathrm{hr})$, which is protein synthesisdependent (Krug et al., 1984; Frey et al., 1988).

Most of the studies investigating the mechanisms of LTP focused on the synapses that display NMDA receptor-dependent LTP. Both in vivo and in vitro studies demonstrate that the mossy fiber (MF)-CA3 synapse displays a form of LTP (MF-LTP) that is NMDA receptor-independent (Harris and Cotman, 1986; Johnston, 1992) and requires opioid receptor activation (Derrick et al., 1991) (but see Salin et al., 1995). Regarding the mechanisms involved in MF-LTP induction, studies suggest that $\mathrm{Ca}^{2+}$ entry is necessary for MF-LTP induction (Williams and Johnston, 1989; Zalutsky and Nicoll, 1990). It is reported that the increase in $\mathrm{Ca}^{2+}$ results in the activation of a second messenger cascade that involves calcium/ calmodulin-dependent adenylyl cyclase activation (Huang et al., 1994; Weisskopf et al., 1994), a rise in cAMP, and the activation of cAMP-dependent protein kinase (Weisskopf et al., 1994).

Recent findings in vitro report that MF-LTP similarly expresses

Received May 31, 2000; revised Aug. 21, 2000; accepted Aug. 21, 2000.

This research was supported by National Institute of Drug Abuse Grant DA04195 to J.L.M. and Research Centers in Minority Institutions/National Center for Research Resources/National Institutes of Health Award G12RR13646-02 to E.J.B.-R. We acknowledge the assistance offered by Dr. Brian E. Derrick during the course of these experiments and the helpful comments of Dr. Sandra Peña de Ortiz.

Correspondence should be addressed to Edwin J. Barea-Rodríguez, Division of Life Sciences, 6900 North Loop, 1604 West, University of Texas at San Antonio, San Antonio, TX 78249-0616. E-mail: ebarea@utsa.edu.

Copyright (C) 2000 Society for Neuroscience $0270-6474 / 00 / 208528-05 \$ 15.00 / 0$ an early-protein-independent and a late-protein-dependent phase (Huang et al., 1994). The time course of MF-LTP measured in vivo is also different from that measured in vitro. The asymptote of MF-LTP potentiation in vitro is observed immediately after the delivery of the trains (Jaffe and Johnston, 1990; Huang et al., 1994; Weisskopf et al., 1994; Urban and Barrionuevo, 1996). In contrast, MF-LTP in vivo is characterized by an initial potentiation, which develops slowly over time and only reaches a maximum augmentation in EPSP slope in $\sim 1 \mathrm{hr}$ after high-frequency stimulation (Derrick et al., 1991). This suggested to us that the processes underlying the induction of MF-LTP measured in vivo may be different from that measured in vitro.

In the present study, we tested the hypothesis that MF-LTP induction is fundamentally different from that observed in both NMDA receptor-dependent systems and MF-LTP induced in vitro by characterizing the effect of the protein synthesis inhibitors anisomycin and cycloheximide on the induction of MF-LTP in in vivo anesthetized rats. We report that protein synthesis inhibition blocks the induction of MF-LTP in a dose-dependent manner. These findings suggest that, in vivo, protein synthesis is necessary for MF-LTP induction.

\section{MATERIALS AND METHODS}

Animals. Adult male Sprague Dawley rats (Simonsen, Gilroy, CA and Harlan Sprague Dawley, Indianapolis, IN), weighing 350-400 gm on arrival, were housed individually, with food and water available ad libitum. The animals were maintained on a $12 \mathrm{hr}$ light/dark cycle. Animals were anesthetized with Nembutal (65 mg/kg, i.p.) and given supplemental pentobarbital injections $(6.5 \mathrm{mg} / \mathrm{kg})$ at $1 \mathrm{hr}$ intervals to maintain a surgical level of anesthesia. Body temperature was maintained at $37^{\circ} \mathrm{C}$ with a heating pad.

Extracellular mossy fiber CA3 evoked responses. A 33 ga stainless steel cannula-recording electrode was placed above the CA3 pyramidal layer of the dorsal hippocampus [anteroposterior (AP), $-2.9 \mathrm{~mm}$; mediolateral (ML), $2.2 \mathrm{~mm}$ (Paxinos and Watson, 1986)] using a stereotaxic instrument (Kopf, Tujunga, CA). The combination of cannula-recording electrode was constructed by insulating (Epoxylite, Irvine, CA) the outside of the cannula, except at the tip and $3 \mathrm{~cm}$ from top. In the top noninsulated area, a stainless steel wire was wrapped around the cannula and connected to the amplifier via an amphenol connector. Plastic tubing was attached to the top aperture, and it was used to deliver the drugs. This cannula-recording electrode allowed us to deliver drugs exactly in the same area in which the evoked responses were collected. Responses were evoked via direct stimulation of the mossy fibers using a stainless steel bipolar stimulating 
electrode ( 0.005 inch diameter), at coordinates corresponding to the orientation of mossy fiber projections (AP, $-3.5 \mathrm{~mm}$; ML, $2.0 \mathrm{~mm}$ ). Constant current stimulation (10-50 $\mu \mathrm{A}$ monophasic pulses, $0.2 \mathrm{msec}$ duration) was provided by a Grass S48 stimulator, delivered to the stimulating electrode through a Grass Stimulus Isolation Unit (PSIU6).

Dorsoventral coordinates for the stimulating and recording electrodes were determined as described previously (Derrick et al., 1991). An electrode was placed initially in the granule cell layer of the dentate gyrus with the aid of stereotaxic coordinates and audio monitoring of CA1 pyramidal cell and dentate granule cell injury-induced unit discharges. A second electrode then was lowered into the CA3 region $(3.1-3.3 \mathrm{~mm}$ below the brain surface). Stimulation was delivered at a rate of $0.35 \mathrm{~Hz}$ until antidromic spikes resulting from mossy fiber stimulation (2-3 msec to peak) were observed in the dentate. Orthodromic responses then were evoked by delivering stimulation through the dentate electrode and recording from the CA3 electrode. The stimulating electrode was adjusted until a characteristic mossy fiber field EPSP was observed consisting of a small $(\sim 0.5 \mathrm{mV})$ negative potential that is easily elicited with low $(10-50$ $\mu \mathrm{A}$ ) current intensities and that displays an onset of 3-4 msec and a peak at $\sim 8-10 \mathrm{msec}$. Synchronous mossy fiber population spikes superimposed on field EPSPs were not observed, either at relatively high stimulation intensities $(>70 \mu \mathrm{A})$ or after high-frequency stimulation.

The evoked responses were amplified on a Grass P5 series alternating current preamplifier, filtered at $0.1 \mathrm{~Hz}-3 \mathrm{kHz}$, digitized $(10$ points $/ \mathrm{msec})$ using a microcomputer, and then stored for off-line analysis using DataWave software (DataWave Technologies, Longmont, CO). The current intensity that elicited a 50\% maximal response in each animal was determined and used for all subsequent stimulation, including high-frequency stimulation to induce LTP. To measure treatment effects, responses were evoked once every $20 \mathrm{sec}$ throughout the entire experiment, and slope measures were calculated.

Drug treatment. After a 20 min baseline period, anisomycin $(0.04,10$, or $40 \mathrm{nmol} ; 1 \mu \mathrm{l}$ total volume) (Sigma, St. Louis, MO) or cycloheximide (40 $\mathrm{nmol} ; 1 \mu$ l total volume) (Sigma), prepared in lactated Ringer's solution, were delivered into the stratum lucidum of hippocampal area CA3 via pressure ejection. One group of animals received anisomycin in the stratum lucidum of the contralateral CA3 to ensure that any effect observed was not attributable to anisomycin diffusion outside of the tetanized pathway. To ensure that the recordings were from mossy fibers-evoked responses, a group of animals received the NMDA-receptor blocker $( \pm)$ (3-(2-carboxypiperazin-4-yl) (CPP) $(10 \mathrm{mg} / \mathrm{kg}$, i.p.). This dose of CPP blocks NMDA receptor-dependent LTP in vivo (Hernandez et al., 1994). For both protein synthesis inhibitors used, the solution was delivered over a 5 min period, using a cannula-recording electrode. This drug infusion period was followed by a 15 min postdrug period and then by the delivery of high-frequency stimulation. LTP was induced by delivering highfrequency stimulation of two $100 \mathrm{~Hz}$ trains, with an intertrain interval of $20 \mathrm{sec}$ (200 total pulses). To measure the development of LTP, evoked responses were collected for an additional $1 \mathrm{hr}$.

Verification of electrode placement. Electrode placement was verified using both electrophysiological and histological criteria. The electrophysiological criteria involved the audio localization of CA1, CA3, and dentate gyrus cell fields, the observation of an evoked antidromic response in the dentate gyrus (observed when stimulating CA3 and recording in the dentate gyrus), and the presence of mossy fiber-evoked responses preceded by a presynaptic volley (observed when stimulating in the dentate gyrus and recording in area CA3). Ten percent of the animals were subjected to histological analysis. The brains were extracted, frozen, and cut coronally at a thickness of $40 \mu \mathrm{m}$ using a microtome. Once the electrode tracks were visible, every fifth section was saved and mounted on slides. The tracks made by the stimulating and recording electrodes were reconstructed by displaying the section with a projection microscope onto photocopies of the rat brain stereotaxic atlas. For these animals, the electrodes were correctly placed $100 \%$ of the time.

Measurement of protein synthesis inhibition. Anisomycin was dissolved in an aqueous solution containing $\left[{ }^{35} \mathrm{~S}\right]$ methionine $(10 \mu \mathrm{Ci} / \mu \mathrm{l} ; \mathrm{NEN}$, Boston, MA) and $10 \mathrm{~mm} \beta$-mercaptoethanol, a stabilizer. Drug administration and electrophysiological procedures were the same as described above. The final dose of anisomycin administered was $0.04,10$, or $40 \mathrm{nmol}$. One hour after the delivery of high-frequency stimulation, the animal was decapitated, and the entire hippocampus, ipsilateral to the stimulation-recording site, was quickly dissected on ice-cold PBS, $\mathrm{pH}$ 7.0. Protein synthesis inhibition was measured using similar methods as described previously (Otani et al., 1989). The tissue sample was homogenized by sonication in $5 \mathrm{vol}$ of cold protease-free lysis buffer $(5 \%$ SDS, $312 \mathrm{~mm}$ Tris-Cl, $312 \mathrm{~mm}$ imidazole, $200 \mathrm{~mm}$ dithiothreitol, and 50\% glycerol) and further diluted in $5 \mathrm{vol}$ of protease-free water, followed by boiling for $2 \mathrm{~min}$. Cellular debris was removed by centrifugation $(7000 \mathrm{rpm}$ for $20 \mathrm{~min}$ at room temperature), and the supernatant was collected. Total radioactivity in the supernatant was determined and compared with radiolabel incorporated into the trichloroacetic acid precipitable cellular protein fraction (Bonifacino, 1993). The percent ratio of these two samples (TCA and non-TCA treated) was calculated for each group. The percent ratio calculated for each sample was expressed as the percentage value of the Ringer's solution-treated animals (Ringer's-anisomycin/Ringer's $\times 100$ ).

Whole-cell recording. Hippocampal slices $(300 \mu \mathrm{m})$ were harvested from 15-to 30-d-old Sprague Dawley rats and maintained in vitro as described previously (Chitwood and Jaffe, 1998). Slices were maintained at room temperature in oxygenated $\left(95 \% \mathrm{O}_{2}-5 \% \mathrm{CO}_{2}\right)$ artificial CSF (aCSF) containing (in $\mathrm{mM}$ ): 124 choline chloride, $2.5 \mathrm{KCl}, 26 \mathrm{NaHCO}_{2}, 3 \mathrm{MgCl}_{2}$, $3 \mathrm{CaCl}_{2}, 1.25 \mathrm{NaHPO}_{4}$, and 10 dextrose. Slices were transferred as needed to a submersion-type recording chamber perfused with oxygenated aCSF $(\sim 1 \mathrm{ml} / \mathrm{min})$, also at room temperature.

The recording chamber was mounted on an upright microscope (Axioskop; Zeiss, Oberkochen, Germany) to visualize CA3 pyramidal neurons using infrared video-differential interference contrast microscopy (Stuart et al., 1993). Whole-cell patch-clamp recordings were made using pipettes containing (in mM): $150 \mathrm{~K}$-gluconate, $20 \mathrm{KCl}, 0.1-1$ EGTA, $2 \mathrm{MgCl}_{2}, 2$ $\mathrm{Na}_{2}$ ATP, and 10 HEPES, pH 7.3. Electrodes were backfilled with the same solution containing $100 \mu \mathrm{M}$ the calcium-sensitive dye fura-2. Electrical recordings were measured using an Axoclamp 2b (Axon Instruments, Foster City, CA) in bridge current-clamp mode and digitized using an Instrutech ITC-16 board (Instrutech, Great Neck, NY) connected to a Power Macintosh computer (Apple Computer, Cupertino, CA) running AxoData (Axon Instruments) acquisition software. Analysis of electrical data were performed using custom software written with Igor Pro (Wavemetrics, Lake Oswego, OR).

Fura-2 was excited by a xenon lamp at $380 \mathrm{~nm}$, and emission was detected at wavelengths greater than $512 \mathrm{~nm}$ using a cooled CCD camera (PXL-37; Photometrics, Tucson, AZ) in frame transfer mode. Software for this camera was provided by Dr. Joseph Callaway (University of Tennessee, Memphis, TN). Changes in intracellular calcium were determined at a single excitation wavelength $(380 \mathrm{~nm})$ by normalizing changes in fluorescence $(\Delta F)$ to resting fluorescence levels $(F)$ and reported as percent $\Delta F / F$. Autofluorescence was determined from a nondendritic region lacking any changes in fluorescence signal or from fluorescence sequences taken 200-300 $\mu \mathrm{m}$ away from the filled cell with the same laminar register within CA3. Bleaching was corrected by subtracting control images without electrical or synaptic stimulation. Calcium imaging, electrical stimulation, and data acquisition were coordinated using the Master-8 stimulus generator (A.M.P.I., Jerusalem, Israel)

Data analysis. The effect of the protein synthesis inhibitor anisomycin on the induction of MF-LTP was measured by comparing the percent change in the EPSP slope in the last $5 \mathrm{~min}$ of the baseline period with the last 5 min of the $1 \mathrm{hr}$ collection period. This percent change was calculated using a trimmed mean. Inherent in in vivo recordings are physiological artifacts (heartbeat, synchronous firing of pyramidal cells) that sporadically can alter evoked responses slopes. Trimming of means is an accepted technique (Wainer, 1982) for reducing sample variability and minimizing the contribution of these sources of spurious signals. The calculation of the trimmed mean is conducted by eliminating the highest and the lowest numbers from the distribution, including the last $5 \mathrm{~min}$ of the baseline and the last $5 \mathrm{~min}$ of the 1 or $2 \mathrm{hr}$ (CPP-treated group) collection period. The significance of the percent change values in the EPSP slope and the percent changes of $\left[{ }^{35} \mathrm{~S}\right]$ methionine incorporation was determined using a one-way ANOVA. Data from the groups that received cycloheximide, CPP alone, nonpotentiated control with anisomycin, or anisomycin in the contralateral CA3 side were analyzed using a dependent Student's $t$ test to determine whether post-treatment and post-tetanization responses were different from those recorded during the baseline period. An independent Student's $t$ test was used to compare post-tetanization responses between the group that received anisomycin in the contralateral CA3 and the Ringer's solution-treated control. A one-way repeated measure ANOVA was used to analyze the anisomycin-treated but not potentiated group. Measurements were obtained at 20,40 , and 80 min periods.

\section{RESULTS}

In these experiments, we investigated whether protein synthesis is required for the induction of MF-LTP in vivo. The protein synthesis inhibitor anisomycin was delivered into hippocampal area CA3 before administration of high-frequency stimulation. We found that anisomycin blocked the induction of mossy fiber long-term potentiation in a dose-dependent manner. There was no significant difference found between Ringer's- and anisomycin- $(0.04 \mathrm{nmol})$ treated animals with the lowest dose $\left(F_{(1,8)}=0.924 ; p>0.05\right)$. Both groups displayed MF-LTP that lasted for the duration of the experiment (Fig. $1 A, B)$.

Both $10 \mathrm{nmol}\left(F_{(1,8)}=6.709 ; p<0.03\right)$ and $40 \mathrm{nmol}\left(F_{(1,10)}=\right.$ $10.00 ; p<0.01)$ of anisomycin effectively blocked the induction of MF-LTP when compared with Ringer's control (Fig. 1C,D). There were no significant differences between the animals that received either 10 or $40 \mathrm{nmol}$ of anisomycin $\left(F_{(1,10)}=0.042 ; p>0.05\right)$.

The inhibitory effect of anisomycin on protein synthesis was determined by measuring the incorporation of $\left[{ }^{35} \mathrm{~S}\right]$ methionine into newly synthesized proteins. Anisomycin at doses of 0.04, 10, and 40 nmol resulted in 21,82 , and $83 \%$ protein synthesis inhibition, respectively. Both $10 \mathrm{nmol}\left(F_{(1,4)}=9.284 ; p<0.04\right)$ and 40 $\mathrm{nmol}\left(F_{(1,4)}=8.856 ; p<0.04\right)$ of anisomycin produced significant 
Figure 1. Inhibition of protein synthesis by anisomycin blocks the induction of MF-LTP. $A$, Induction of MF-LTP after the injection of Ringer's solution $(n=5)$. $B$, A low dose of anisomycin $(0.04 \mathrm{nmol})$ does not block the induction of MF-LTP $(n=7)$, whereas higher doses of $10(n=5)$ or $40(n=7)$ nmol block its induction $(C$, $D)$. Representative traces for each panel were taken 1 min before and $60 \mathrm{~min}$ after high-frequency stimulation. Calibration: $0.5 \mathrm{mV}, 5 \mathrm{msec}$.
Figure 2. The effect of anisomycin is localized ipsilateral to the injected side. $A$, Administration of anisomycin into the $\mathrm{CA} 3$ region of the contralateral hippocampus had no effect on MF-LTP $(n=4)$. B, MF-LTP is induced in animals that received the NMDA receptor antagonist CPP $(10 \mathrm{mg} / \mathrm{kg}$, i.p.). $C$, Injection of the protein synthesis inhibitor cycloheximide $(40 \mathrm{nmol})$ also blocked the in duction of MF-LTP $(n=5)$. $D$, Anisomycin does not affect low-frequency evoked responses. Representative traces for each panel were taken 1 min before and 60 or 120 (CPP group) min after high-frequency stimulation. Calibration: $0.5 \mathrm{mV}, 5 \mathrm{msec}$.
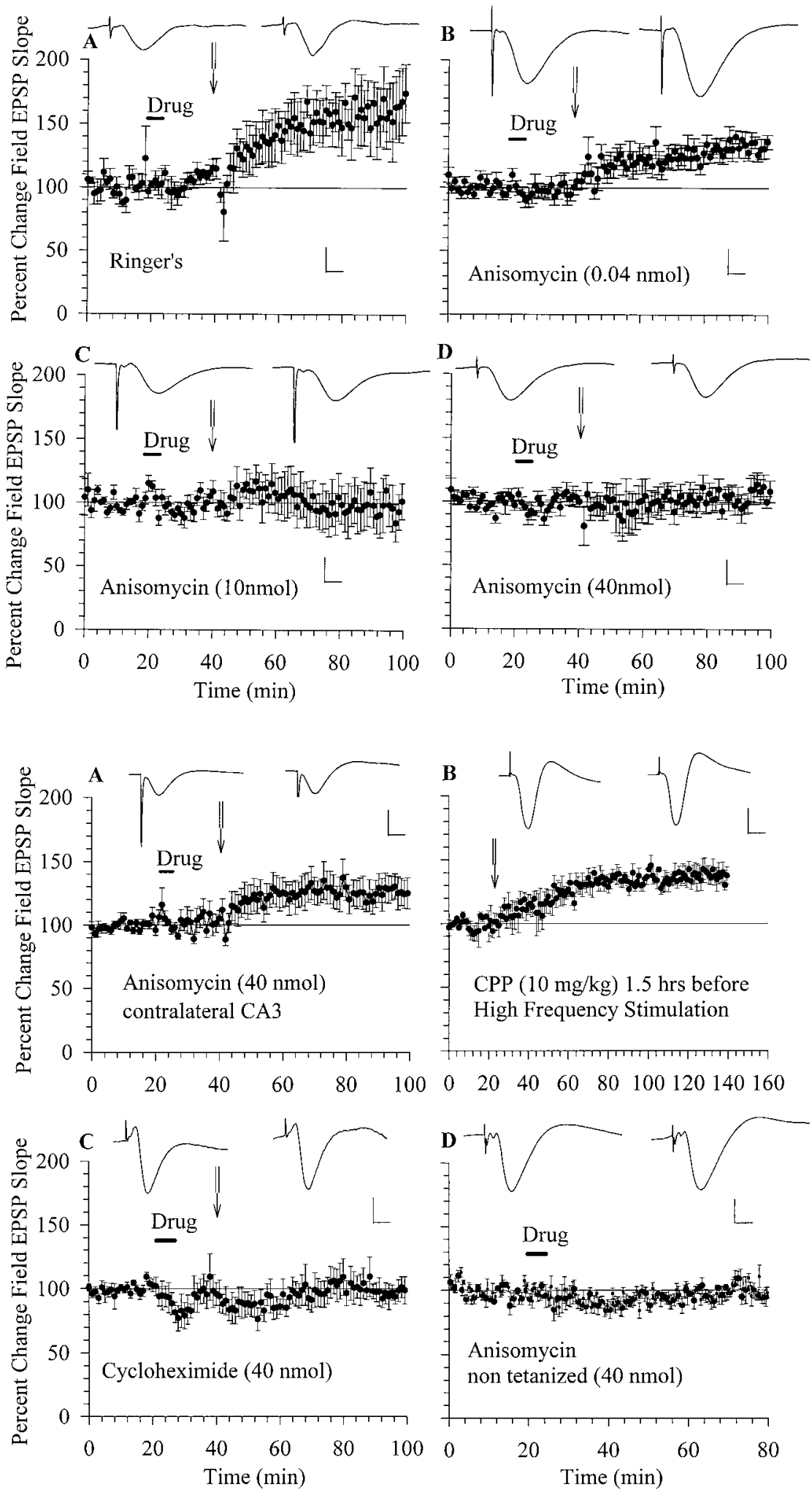

decreases in the level of protein synthesis compared with subjects treated with $\left[{ }^{35} \mathrm{~S}\right]$ methionine. The level of protein synthesis inhibition produced by the dose of 0.04 nmol was not significantly different from control $\left(F_{(1,4)}=0.591 ; p>0.05\right)$.

Anisomycin $(40 \mathrm{nmol})$ delivered into the contralateral CA3 region did not block the induction of MF-LTP ipsilateral to the stimulation side $(t=-2.784 ; \mathrm{df}=4 ; p<0.05)$ (Fig. $2 A)$. Furthermore, there was no significant difference found between the group that received anisomycin in the contralateral CA3 and the Ringer's solution-treated control $(t=-2.3031 ; \mathrm{df}=8 ; p>0.05)$. MF-LTP was observed in animals that received the NMDA receptor antagonist CPP $(t=-6.871$; df $=3 ; p<0.05)$ (Fig. $2 B)$, and the potentiation lasted for the entire length of the experiment $(2 \mathrm{hr})$. The protein synthesis inhibitor cycloheximide at a concentration of $40 \mathrm{nmol}$ also blocked the induction of MF-LTP $(t=0.370$; $\mathrm{df}=3$; $p>0.05$ ) (Fig. 2C). A one-way ANOVA found no significant changes in the anisomycin-treated nonpotentiated group $\left(F_{(2,6)}=\right.$ 4.130; $p>0.05$ ) (Fig. 2D). 


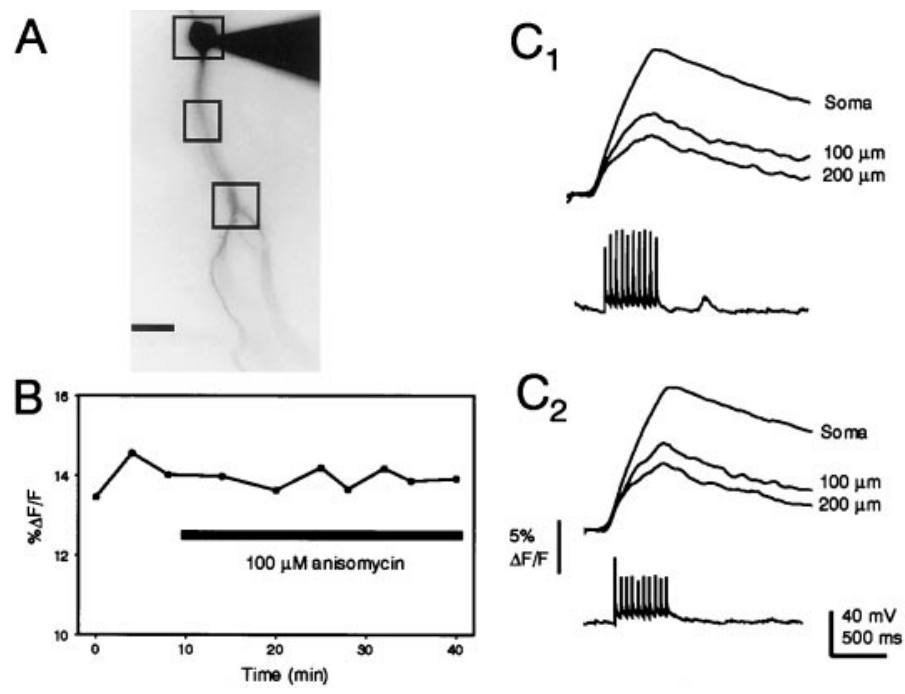

Figure 3. Anisomycin does not affect voltage-gated calcium entry. $A$, Micrograph of a CA3 pyramidal neuron. The patch electrode filled with fura- 2 is visible at the top. The three squares represent regions of interest for measuring changes in fluorescence at the soma, $\sim 100$ and $200 \mu \mathrm{m}$ from the soma. Scale bar, $100 \mu \mathrm{m}$. $B$, Time course of somatic $\Delta F / F$ before and during the application of $100 \mu \mathrm{M}$ anisomycin. $C$, Calcium transients at the soma, 100 and $200 \mu \mathrm{m}$ from the soma in response to 10 action potentials before $\left(C_{1}\right)$ and after $\left(C_{2}\right)$ exposure to anisomycin.

To determine whether anisomycin has nonspecific effects on voltage-gated calcium entry and, in turn, on the potential induction of MF-LTP (Kapur et al., 1998), we next performed experiments using the in vitro hippocampal slice preparation. With the use of standard fluorescence imaging methods, spike-mediated calcium entry into CA3 pyramidal neurons was monitored before and after exposure to $100 \mu \mathrm{M}$ bath-applied anisomycin $(n=3)$. As illustrated in Figure 3, voltage-gated calcium influx into both the soma and dendrites, in response to 10 action potentials, was not affected by exposure to anisomycin.

\section{DISCUSSION}

The present study reveals that anisomycin, when administered 15 min before the delivery of high-frequency stimulation, blocks the induction of MF-LTP in a dose-dependent manner. The inhibitory effect of anisomycin on protein synthesis inhibition was confirmed by measuring the incorporation of $\left[{ }^{35} \mathrm{~S}\right]$ methionine into newly synthesized proteins. The two effective doses of anisomycin, 10 and $40 \mathrm{nmol}$, resulted in 82 and $83 \%$ of protein synthesis inhibition, respectively. The percentages of inhibition effective in blocking MF-LTP induction are comparable with those observed in studies in which protein synthesis inhibition blocked maintenance (Otani et al., 1989) of NMDA receptor-dependent LTP in the dentate gyrus.

It is possible that synaptic responses might be elicited via commissural/association (C/A) fibers caused by the direct activation of CA3 pyramidal neurons by axon collaterals extending into the hilar region (Li et al., 1994). Because LTP at C/A synapses is NMDA receptor-dependent, one group received the NMDA receptor antagonist CPP $(10 \mathrm{mg} / \mathrm{kg})$. Here CPP did not affect baseline responses or the induction of LTP, thus demonstrating that the responses were primarily attributable to the activation of the mossy fibers.

Another explanation to the present results is that anisomycin spread to other areas and that the effect observed was not attributable to the localized administration into the mossy fiber-CA3 synapses but to the effect of protein synthesis inhibition in areas sending projections to the CA3 region, such as the commissural CA3 projections. To address this possibility, a group of animals received anisomycin in the contralateral CA3 region. In this group, anisomycin did not block MF-LTP. This finding indicates that the effect of anisomycin on protein synthesis inhibition was localized to the ipsilateral hippocampus in which it was injected.

Alternatively, the effect of anisomycin on the induction of MFLTP could be attributable to a nonselective action of anisomycin on the physiology of CA3 pyramidal neurons. However, the finding that the administration of another protein synthesis inhibitor, cycloheximide, also blocked the induction of MF-LTP suggests that the effect observed is attributable to protein synthesis inhibition. That is, the two drugs have the same primary action, protein synthesis inhibition, but a different spectrum of side effects. That they have the same effect on MF-LTP increases the confidence that the effect observed is attributable to their common primary action.

Additionally, we investigated whether anisomycin nonspecifically affected calcium entry into CA3 pyramidal neurons. For instance, if anisomycin affects calcium entry into the cell, this could also block MF-LTP, because calcium is necessary for LTP induction at this synapse (Williams and Johnston, 1989; Urban and Barrionuevo, 1996; Kapur et al., 1998). Bath-applied anisomycin did not change calcium flux in pyramidal cells of hippocampal area CA3. Thus, the blockade of the induction of MF-LTP was not attributable to an effect on calcium dynamics.

Because these studies were conducted in the anesthetized animal, it is possible that Nembutal affected protein synthesis. Nembutal-induced protein synthesis inhibition could add to the inhibition observed in the anisomycin-treated animals and thus account for the blockade of MF-LTP. To our knowledge, Nembutal does not affect protein synthesis. All of the measurements of anisomycin-treated animals are compared with the Ringer's group that was also treated with Nembutal and showed LTP.

The findings in the present study are in contrast to those of Huang et al. (1994) who reported that anisomycin blocked the maintenance but not the induction of MF-LTP. The findings from this group may differ from the present results because of significant differences between mossy fiber-LTP induced either in vivo or in vitro. For instance, Huang et al. showed a rapid onset and decremental LTP when one $100 \mathrm{~Hz}$ train was applied and a rapid onset and nondecremental LTP when three $100 \mathrm{~Hz}$ trains were used. In contrast, in our in vivo experiments, nondecremental LTP was triggered by two $100 \mathrm{~Hz}$ trains and augmentation of the response had a very slow onset and took $1 \mathrm{hr}$ to reach its maximum. Thus, the differences in time course might reflect dependence on protein synthesis that is observed during the induction of in vivo MF-LTP and not be required for the induction of in vitro MF-LTP.

The idea that local protein synthesis is involved in mediating synaptic plasticity in the MF-CA3 synapse is supported by the findings that mRNA for proteins such as CaM kinase II are present in the dendrites of this synaptic region (Chicurel et al., 1993). CaM kinase II is implicated in the induction of NMDA receptordependent LTP (Finn and Browning, 1980; Mody et al., 1984), and $\alpha \mathrm{CaM}$ kinase II is implicated in learning and memory (Silva et al., 1992). It is possible that translation of such resident mRNAs may be activated with the stimulation parameters used in our study to induce MF-LTP and that new protein products are required for the development of LTP, which takes $\sim 1$ hr in vivo.

Because new protein synthesis is necessary for the formation of long-term memory (Bennett et al., 1977) and because LTP, a form of synaptic plasticity, may mediate the formation of long-term memory in the brain (Teyler and Discenna, 1984), it is important to understand the role of new protein synthesis in LTP. More importantly, similarities in the role of new protein synthesis in long-term memory and in the induction of LTP would provide convergent evidence supporting a role for LTP in learning and memory processes. In the behavioral literature, a critical level of protein synthesis is required for the formation of long-term memory (Bennett et al., 1977; Quinton and Kramarcy, 1977). An amnestic effect was observed after the administration of either anisomycin or cycloheximide, when the inhibition protein synthesis was over $80 \%$. Interestingly, a critical level of $80 \%$ protein synthesis inhibition is necessary to block the induction of NMDA receptor-dependent LTP (Deadwyler et al., 1987). In agreement with these observa- 
tions, it is shown here that both 10 and $40 \mathrm{nmol}$ doses of anisomycin, which blocked induction of MF-LTP, produced over $80 \%$ inhibition of protein synthesis.

In summary, we found that the induction of MF-LTP in vivo requires protein synthesis, suggesting that the mechanisms underlying synaptic plasticity under these conditions are different from those observed during the induction of MF-LTP in vitro.

\section{REFERENCES}

Bennett EL, Rosenzweig MR, Flood JF (1977) Protein synthesis and memory studies with anisomycin. In: Mechanisms, regulation, and special function of protein synthesis in the brain (Roberts S, Lajtha A, Gispen W, eds), pp 319-330. Amsterdam: Elsevier/North Holland Biomedical.

Bliss TVP, Lomo T (1973) Long-lasting potentiation of synaptic transmission in the dentate area of the anesthetized rabbit following stimulation of the perforant path. J Physiol (Lond) 232:331-356.

Bonifacino JS (1993) Biosynthetic labelling of proteins. In: Current protocols in molecular biology (Ausubel FM, Brent R, Kingston RE, Moore DD, Seidman JC, Smith JA, Struhl K, eds), pp 10.16.5-10.18.6. New York: Wiley.

Chicurel ME, Terrian DM, Potter H (1993) mRNA at the synapse: analysis of a synaptosomal preparation enriched in hippocampal dendritic spines. J Neurosci 13:4054-4063.

Chitwood RA, Jaffe DB (1998) Calcium-dependent spike-frequency accommodation in hippocampal CA3 nonpyramidal neurons. J Neurophysiol 80:983-988.

Deadwyler SA, Dunwiddie T, Lynch G (1987) A critical level of protein synthesis is required for long-term potentiation. Synapse 1:90-95.

Derrick BE, Weinberger SB, Martinez JLJ (1991) Opioid receptors are involved in an NMDA receptor-independent mechanism of LTP induction at hippocampal mossy fiber-CA3 synapses. Brain Res Bull 27:219-223

Finn RC, Browning M (1980) Trifluoperazine inhibits hippocampal longterm potentiation and the phosphorylation of a 40,000 dalton protein. Neurosci Lett 19:103-108.

Frey U, Krug M, Reymann KG, Matthies H (1988) Anisomycin, an inhibitor of protein synthesis, blocks late phases of LTP phenomena in the hippocampal CA1 region in vitro. Brain Res 452:57-65.

Harris EW, Cotman CW (1986) Long-term potentiation of guinea pig mossy fiber responses is not blocked by $N$-methyl-D-aspartate antagonists. Neurosci Lett 70:132-137.

Harris EW, Ganong AH, Cotman CW (1984) Long-term potentiation in the hippocampus involves activation of $N$-methyl-D-aspartate receptors. Brain Res 323:132-137.

Hernandez RV, Derrick BE, Rodriguez WA, Martinez JLJ (1994) $(+/-)$ CPP, an NMDA receptor antagonist, blocks the induction of commissural-CA3 LTP in the anesthetized rat. Brain Res 656:215-219.

Huang YY, Li XC, Kandel ER (1994) cAMP contributes to mossy fiber LTP by initiating both a covalently mediated early phase and macromolecular synthesis-dependent late phase. Cell 79:69-79.

Jaffe D, Johnston D (1990) Induction of long-term potentiation at hip- pocampal mossy-fiber synapses follows a Hebbian rule. J Neurophysiol 64:948-960.

Johnston D (1992) NMDA-receptor independent LTP. Neurochem Int 20:461-462.

Kapur A, Yeckel MF, Gray R, Johnston D (1998) L-Type calcium channels are required for one form of hippocampal mossy fiber LTP. J Neurophysiol 79:2181-2190.

Krug M, Lossner B, Ott T (1984) Anisomycin blocks the late phase of long-term potentiation in the dentate gyrus of freely moving rats. Brain Res Bull 13:39-42.

Li XG, Somogyi P, Ylinen A, Buzsaki G (1994) The hippocampal CA3 network: an in vivo intracellular labeling study. J Comp Neurol 339:181-208.

Mody I, Baimbridge KG, Miller JJ (1984) Blockade of tetanic-and calcium-induced long-term potentiation in the hippocampal slice preparation by neuroleptics. Neuropharmacology 23:625-631.

Otani S, Marshall CJ, Tate WP, Goddard GV, Abraham WC (1989) Maintenance of long-term potentiation in rat dentate gyrus requires protein synthesis but not messenger RNA synthesis immediately posttetanization. Neuroscience 28:519-526.

Paxinos G, Watson W (1986) The rat brain in stereotaxic coordinates. New York: Academic.

Quinton EE, Kramarcy NR (1977) Memory impairment correlates closely with cycloheximide dose and degree of inhibition of protein synthesis. Brain Res 131:184-190.

Salin PA, Weisskopf MG, Nicoll RA (1995) A comparison of the role of dynorphin in the hippocampal mossy fiber pathway in guinea pig and rat. J Neurosci 15:6939-6945.

Scoville WB, Milner B (1957) Loss of recent memory after bilateral hippocampal lesions. J Neurol Neurosurg Psychiatry 20:11-21.

Silva AJ, Paylor R, Wehner JM, Tonegawa S (1992) Impaired spatial learning in alpha-calcium-calmodulin kinase II mutant mice. Science 257:206-211.

Stuart GJ, Dodt HU, Sakmann B (1993) Patch-clamp recordings from the soma and dendrites of neurons in brain slices using infrared video microscopy. Pflügers Arch 423:511-518.

Teyler TJ, Discenna P (1984) Long-term potentiation as a candidate mnemonic device. Brain Res 319:15-28.

Urban NN, Barrionuevo G (1996) Induction of hebbian and non-hebbian mossy fiber long-term potentiation by distinct patterns of high-frequency stimulation. J Neurosci 16:4293-4299.

Wainer H (1982) Robust statistics: a survey and some prescriptions. In: Statistical and methodological issues in psychology and social science research (Keren G, ed), pp 187-213. Hillsdale, NJ: Erlbaum.

Weisskopf MG, Castillo PE, Zalutsky RA, Nicoll RA (1994) Mediation of hippocampal mossy fiber long-term potentiation by cyclic AMP. Science 265:1878-1882.

Williams S, Johnston D (1989) Long-term potentiation of hippocampal mossy fiber synapses is blocked by postsynaptic injection of calcium chelators. Neuron 3:583-588.

Zalutsky RA, Nicoll RA (1990) Comparison of two forms of long-term potentiation in single hippocampal neurons. Science 248:1619-1624. 